\title{
Teatralidade e Performance na pesquisa em Educação: do corpo e da escrita em perspectiva discursiva ${ }^{1}$
}

\section{Theatricality and Performance in the research in Education: of the body and the writing in discursive perspective}

\author{
Jean Carlos Gonçalves* \\ Michelle Bocchi Gonçalves*
}

\begin{abstract}
RESUMO
O texto pretende fazer uma reflexão sobre a pesquisa em Educação, a partir nas noções de corpo teatralizado/performático e escrita teatralizada/ performática, dimensionando os conceitos de Teatralidade e Performance como dispositivos poético-discursivos para a compreensão de diferentes fenômenos que interessam à esfera educacional. A ancoragem teórica, que perpassa todo o texto, tem nos estudos do discurso e da linguagem sua centralidade investigativa, apontando, sem a pretensão de intersecção entre correntes teóricas, contribuições da Análise do Discurso de linha Francesa e da Análise Dialógica do Discurso, quando estas se deparam com o caráter prismático de objetos e problemáticas da pesquisa em Educação.
\end{abstract}

Palavras-chave: Teatralidade. Performance. Discurso. Pesquisa em Educação.

\footnotetext{
ABSTRACT

The text intends to make a reflection on the research in Education, starting from the notions of theatrical/performative body and theatrical/performative

1 O presente trabalho foi realizado com o apoio do CNPq e da CAPES.

* Universidade Federal do Paraná, Programas de Pós-Graduação em Educação (PPGE) e Educação: Teoria e Prática de Ensino (PPGE:TPEn). Curitiba, Paraná, Brasil. E-mails: jeancarllosgoncalves@gmail.com. http://orcid.org/0000-0003-2826-3366; michellebocchi@gmail.com.http:// orcid.org/0000-0002-2401-8470
} 
writing, dimensioning the concepts of Theatricality and Performance as poetic-discursive devices for the understanding of different phenomena that interest the educational sphere. The theoretical anchorage, which runs through the whole text, has in the studies of discourse and language its investigative centrality, pointing out, without the pretension of intersection between theoretical currents, contributions of the Discourse Analysis of French Line and the Dialogical Analysis of the Discourse, when these are they encounter the prismatic character of objects and problems of research in Education.

Keywords: Theatricality. Performance. Discourse. Research in Education.

\section{Brevíssima introdução}

No enfoque sexual meu corpo e o corpo de outro se fundem numa só carne, mas essa carne única só pode ser interior. É verdade que essa fusão numa carne interior única é o limite a que aspira a minha relação sexual em sua pureza; na realidade ela é sempre complexificada, quer por elementos estéticos de deleite com o corpo exterior, quer, consequentemente, por energias formadoras, criadoras; no entanto o valor artístico que elas criam é aqui apenas um meio e não atinge autonomia e plenitude. É essa a distinção entre os corpos exterior e interior - o corpo do outro e o meu corpo - no contexto fechado concreto da vida de um homem singular, para quem a relação "eu e o outro" é absolutamente irreversivel e dada de uma vez por todas.

(BAKTHIN, M., 2003, p. 48)

O Sujeito é sempre, e ao mesmo tempo, sujeito da ideologia e sujeito do desejo inconsciente e isso tem a ver com o fato de nossos corpos serem atravessados pela linguagem antes de qualquer cogitação. (HENRY, P., 1992, p. 188)

O presente texto tem por objetivo principal dimensionar os conceitos de Teatralidade e Performance em sua aplicação ao campo da pesquisa em Educação, refletindo sobre as noções de corpo teatralizado/performático e escrita teatralizada/performática em sua relação com os estudos discursivos.

A Teatralidade é considerada, neste trabalho, com base nos pressupostos de Cornago (2009) e Diéguez (2014), para os quais é necessário pensar o próprio teatro como campo expandido, ou seja, é urgente o olhar para manifestações contemporâneas daquilo que é intrinsecamente teatral, mas não se encontra, necessariamente, atrelado à prática teatral in situ. Empreender a Teatralidade 
como dispositivo analítico emerge como possibilidade de se (re)pensar as práticas naturalizadas em diferentes contextos, identificando nelas efeitos relacionados a um discurso teatral (este compreendido, também, em uma acepção ampla, que extrapola os limites da própria noção de teatro) (GONÇALVES, 2014). Vislumbrar, então, efeitos de Teatralidade como dispositivo analítico para pensar a Educação encontra nas discussões de Florence (2011) um lugar de equilíbrio, especialmente na abordagem do autor sobre o teatro como uma arte capaz de acordar o imaginário e questionar por vias radicais qualquer instituição ou convenção que possa reger as relações humanas.

À Performance interessa o conhecimento educacional que toma a escolaridade do corpo como ponto de partida e a compreensão da Pedagogia Performativa como uma teoria que pode ser plenamente integrada e estudada do início ao fim do processo de aprendizagem. A Performance tem se estabelecido, especialmente no campo da Educação, enquanto forma de comunicação multicêntrica e periférica (PEREIRA, 2012). Apresentando-se como dispositivo capaz de dar visibilidade às marcas de história e cultura impressas sobre um corpo, o panorama dos Estudos da Performance só pode ser compreendido por intermédio de uma visão expandida, intercultural, histórica, atemporal, ritual, política e sociológica (LIGIÉRIO, 2012). Estudar Performance é interessar-se por marcas identitárias que remodulam e ressignificam sujeitos, considerando seus corpos e suas narrativas com base em diferentes papéis sociais que exercem e/ou lugares sociais que ocupam. É aí que se torna central compreender a Performance como fronteira entre arte e vida, na qual há lugar para resistências, diferenças e críticas culturais.

O artigo se subdivide em duas seções. A primeira discute a noção de corpo teatralizado/performático e a segunda de escrita teatralizada/performática. Tais seções carregam, como transversalidade, diálogos com algumas categorias fundantes da Análise do Discurso de linha Francesa (Michel Pêcheux) e da Análise Dialógica do Discurso (Mikhail Bakhtin e o Círculo), sem buscar conexões entre tais correntes teóricas, mas no intuito de delinear percursos possíveis para a realização de pesquisas educacionais de cunho poético-discursivo no que tange aos procedimentos metodológicos e à análise dos dados.

\section{Corpo teatralizado/performático}

O ponto de vista da Análise de Discurso de linha Francesa (AD) é de interesse à compreensão do processo de como o conhecimento e a sociedade 
constituem-se por meio da linguagem. Por meio da retomada de alguns aspectos históricos e epistemológicos que caracterizam a $\mathrm{AD}$ como um campo teórico-metodológico de estudo da linguagem, discute-se a intersecção do discurso, do sujeito e da história na elaboração e análise de sentidos.

Para Oliveira e Almeida (2008, p. 276), a AD "nos auxilia a entender que a relação pensamento/linguagem/mundo não é direta, mas medida pelo discurso." O professor, nessa perspectiva, é um sujeito produtor de sentidos nas suas relações com o saber e com a linguagem. Como professor, é um sujeito que tem muito a dizer, e as hipóteses prováveis de qualquer pesquisa realizada com esse sujeito no contexto educacional são de que esses dizeres estarão repletos de efeitos de sentidos, e estes, por sua vez, estarão atravessados por outros discursos, por outros dizeres (de alunos, pais, professores, técnicos e toda a estrutura de recursos humanos que circunda a esfera escolar).

Para a Análise Dialógica do Discurso (ADD), o sujeito está sempre situado em um horizonte ideológico e por ele se constitui. Ao falar do crítico literário como sujeito valorativo, por exemplo, Medviédev aponta que quanto mais intenso, difícil e tempestuoso for o seu processo de constituição, mais interessada e comprometida será sua relação com o outro, com a vida, com a obra de arte (MEDVIÉDEV, 2012). Para o autor, a noção de horizonte ideológico está em constante formação, o que permite que o homem se entregue à dialogicidade da vida viva, ou seja, mesmo quando escolhe uma verdade como indiscutível e toma um caminho (ou um lado) como evidente, no percurso da vida ele se depara com o fluxo da constituição ideológica, que "voltará a colocá-lo diante de dois caminhos duplos, duas verdades, e assim por diante." (MEDVIÉDEV, 2012, p. 63).

O olhar para as discursividades, neste artigo, assume a perspectiva de que não é possível desvincular, seja por qualquer dimensão ou plano expressivo, corpo e discurso, pois corpo e discurso realizam o próprio homem e a ele se integram indissociavelmente. Ambos se constituem, se complementam e produzem materialidades passíveis de análise. É aí que a Teatralidade e a Performance são defendidas, aqui, como possíveis espaços de inscrição dos sujeitos no mundo e nas suas comunidades. No caso da pesquisa em Educação, a Teatralidade e a Performance podem colocar em discussão os saberes finitos e ilusórios sobre a aprendizagem como algo isolado, cumulativo e/ou linear, discutindo os processos de aprender em suas relações marcadas por jogos de linguagem e por motivações poético-performativas, incluindo aí corpo, gesto e imaginação como manifestações discursivas nem sempre transparentes e, consequentemente, nem sempre identificáveis ou analisáveis.

Orlandi (2014), ao escrever sobre o Parkour como reescrita do sujeito e sua relação com o corpo e com o espaço, faz alguns apontamentos que se 
aproximam bastante da concepção de discurso que esse artigo pretende abordar. No caso da Performance enquanto discurso, é importante que se assuma que ela se constitui enquanto forma material de significação do sujeito no mundo; forma esta, transpassada por seu corpo, em formulação inscrita em um espaço-tempo. Enquanto o Parkour, estética urbana pela qual o sujeito se inscreve corporalmente no espaço da cidade/metrópole, é um espaço de dizer, os sujeitos da pesquisa em Educação se inscrevem discursivamente, com seus corpos, em seus espaços de formação e/ou docência, marcados simbolicamente pelo caráter histórico-educacional como propulsor de sentidos. Seus trajetos em Educação, que os marcam, os constituem, os formam, estabelecem, também, outra relação com seus corpos em uma perspectiva de Teatralidade e de Performance, pela qual espaço, sujeito, movimento e sentido se tornam presentificados discursivamente.

É por uma expectativa de mobilização dos conceitos de espaço, tempo e discurso, que Orlandi sugere a noção de espaços narrativos, sempre em construção, pelos quais os sujeitos podem encontrar formulações próprias aos seus lugares de vida. Da mesma maneira que o Parkour pode ser visto como um modo de dizer que transcende espaços burocráticos do urbano tradicional, a Teatralidade e a Performance são, aqui, defendidas como orientações interessadas na ação comunicativa do corpo, sendo que, entre suas principais características está o traço autoral, ligado sempre à presença, ao corpo, à cultura, que marca, assim, as identidades dos sujeitos em suas circunstâncias transitórias de existência pessoal, social, política e tecnológica.

A noção de autoria, inclusive, interessa às discussões propostas neste artigo em sua vinculação a uma noção de sujeito interpelado/atravessado e/ou constituído pelo outro. Para Bakhtin "não se pode representar adequadamente o universo ideológico do outro sem permitir que ele mesmo ressoe, sem revelar sua própria palavra" (BAKHTIN, 2015, p. 127). Compreender o sujeito colaborador de uma pesquisa como autor é dar-lhe voz e situá-lo enquanto figura autônoma, mesmo que repleta de outras vozes, de outros sujeitos, de outras memórias... Nesse ponto, a Teatralidade se apresenta como um meio de comunicação inserido em uma formação ideológica que, para a perspectiva bakhtiniana, se efetiva enquanto "tensa luta que em nós se desenvolve pelo domínio de diferentes pontos de vista, enfoques, tendências e avaliações verboideológicas.” (BAKHTIN, 2015, p. 140)

Sagaseta (2014), ao discutir a Performance como conceito híbrido e não fixo, retoma as contribuições de Erika Fischer-Litche no sentido de ressaltar a noção de acontecimento. É por meio de uma perspectiva de imprevisibilidade ou de fratura do universo previsível que a Performance se apresenta como evento/ ocorrência que inclui trajetos e modos de impressão do corpo no espaço e encontra, consequentemente, discursividades de um sujeito que se conta, que se diz, que se narra. Já, para Orlandi (2014, apud 2001, p. 77) o sujeito é parte do 
acontecimento do significante. Para a autora, interessa a "tomada dos lugares, dos momentos que precisam de sentidos e que se significam, seja pela arte, pela desorganização do discurso ordinário, ou pela violência que desorganiza o imaginário".

Morson (2015) amplia a noção de acontecimento, valendo-se do viés bakhtiniano, chamando a atenção para o fato de que criatividade e diálogo sempre dependerão da existência de um "excedente (uzbutok)". É aí que se apresenta o termo "acontecimentalidade (sobytiinost)":

\begin{abstract}
Nem todos os acontecimentos tem "acontecimentalidade". Um acontecimento tem acontecimentalidade se, e somente se, a presenticidade tiver importância; somente se o momento presente for algo mais do que o resultado automático de momentos anteriores. Só então pode o momento presente ter peso real e constituir, de fato, uma força própria.[...] Acontecimentalidade, criatividade e o excedente criam um mundo que Bakhtin chama de "não finalizabilidade (nezavershennost). (MORSON, 2015, p. 120).
\end{abstract}

Pensar a Teatralidade e a Performance (em perspectiva discursiva) como acontecimento/acontecimentalidade implica colocá-los em um lugar de fronteira, no qual a indistinção entre o corpo do sujeito e corpo da cidade/lugar é baliza necessária. Ou seja, se houver silenciamento de uma das partes, seja do sujeito ou do espaço, de alguma forma haverá um flagrante discursivo. Nesse ponto, a convergência temática com o que Diéguez (2014b) aponta ao discutir a noção de Teatralidade é absolutamente relevante para a mobilização de uma poética de pesquisa em Educação, especialmente por sua insistência por uma aproximação aos "processos vivos da teatralidade", que resulta em pesquisas que possam se alocar fora de espaços convencionais ou seguros, negando separações entre os atores, os teóricos e os investigadores (2014b, p. 6) e assumindo que "nas operações que buscam revelar os mecanismos provocadores da teatralidade, se instala a dimensão performativa." (2014b, p. 6,8)

Trabalhar no campo da Teatralidade e da Performance implica, nesse sentido, compreender, por meio das contribuições de Orlandi (2014), que espaço, corpo e movimento determinam a estrutura e o funcionamento do discurso, catalizando os processos de significação, deslocando e desestabilizando sentidos de uma determinada formação discursiva, em uma trilha que vê o corpo como materialidade específica de significação do sujeito em sua relação com o espaço e o movimento. 
Tanto os dispositivos poético-discursivos da Teatralidade quanto os da Performance possibilitam ao sujeito, que se significa, e ao espaço, que torna possível essa textualização, a oportunidade de atribuir sentidos abertos e propensos a diferentes gestos de interpretação, incluindo aí, a interpretação de si, aliada ao reconhecimento e à autocontemplação de sua realidade enquanto sujeito que toma posse de um espaço específico, com um corpo único por meio de uma posição situada e exclusiva. "O sujeito, em uma escrita de si, se significa, significando a cidade pelo traçado que faz, nele, a cidade significar. Metaforização em corpo e movimento" (ORLANDI, 2014, p. 82). Assim, ganha lugar de discursividade, a memória, que se diz, no desencadear de um processo identitário, apoiada em um modo de subjetivação do sujeito que afirma o seu pertencimento, em espaços de interpretação que agem como metáfora na narrativa de seu próprio corpo. A prática discursiva surge, então, como materialidade do corpo em movimento, e se textualiza na materialidade do espaço: Teatralidade e Performance compreendidas, então, como práticas de narrativa de um corpo cronotopicamente conectado ao espaço, em movimento circular e inacabado de autoria.

A discussão central deste artigo se interessa por corpos que se textualizam no lugar (ou não lugar), de modo que não seja possível empreender corpo, sujeito e esfera de produção (ou condição de produção) em locais separados. A complementaridade, aqui, é regra, porque o sujeito "em sua materialidade, inscreve-se enquanto corpo como um significante de si, inseparável do traçado que o metaforiza" (ORLANDI, 2014, p. 82). A forma material, que se faz narrativa, conjuga-se ao corpo em um atravessamento interdiscursivo que funciona como outro modo de olhar para os dados e de conceber a própria análise na pesquisa em Educação, pelo qual se torne possível pensar o corpo simbólico para além do corpo empírico do sujeito: posição-sujeito.

O deslize de sentidos entre corpo do sujeito, história e espaço oferece ao universo da interpretação diversas formas de olhar para as narrativas de si e, inclusive, formas de narrar-se, seja por planos expressivos já conhecidos e aceitos pela tradição, como o texto escrito, ou por dimensões ainda pouco exploradas pelo mundo científico: Teatralidade e Performance, por exemplo. Pensar que nesses diferentes planos o sujeito encontra lugares de autoria é dar-lhe, também, o direito de se afirmar e se escrever, inscrevendo-o no campo da linguagem de modo que possa, ele mesmo, deixar-se dizer, por intermédio de sua formação discursiva e do ultrapassar fronteiras delimitadas por processos hegemônicos e coercitivos, tão característicos de contextos e instituições educacionais.

A posição-sujeito pode ser referida aqui como um processo de infiltração do sujeito do discurso em uma camada antes pouco tocável, que permita a ressignificação e a reconstrução de sentidos em um processo pelo qual o corpo possa ser entendido como movimento de identidade. Ao escrever-se, ao dizer de si 
em uma perspectiva de Teatralidade e/ou de Performance, o sujeito pontua seus modos de ocupar o espaço e de se relacionar com as práticas culturais das quais participa. Essa dinâmica é capaz de deslocar o gesto, o corpo e sua identidade (ORLANDI, 2014) e interrogar as maneiras de ser em diferentes contextos de vivência e experiência, apontando para a interrogação da própria materialidade do corpo e suas formas de significação. Partindo de uma perspectiva que assume a governabilidade pela sociedade das palavras, dos corpos e gestos, tendo os trajetos sociais e percursos históricos como marcadores de identidade, a pesquisa em Educação pode, então, pensar o corpo não como objeto, mas como situação e tomada de posse do mundo.

Retomando, por exemplo, a noção de alteridade, discutida ao longo da obra de Bakhtin e o Círculo torna-se possível pensar um corpo que, ao mover-se na interação encontra os pressupostos de sua constituição, ou seja, para a pesquisa em Educação, é urgente pensar as relações humanas, consequentemente físicas, de contato, que estão em jogo quando sujeitos de variados lugares, ruas, bairros, comunidades se encontram com o intuito de conectarem-se ao saber, ao conhecimento. Mais do que dispostos em uma sala de aula, os corpos dos diferentes sujeitos da Educação vinculam-se compartilhando histórias, movimentos, gestualidades, ficções de si e pontos de vistas sobre seus pares.

Pensar o lugar do corpo e(m) Teatralidade e Performance na Educação carece, assim, de um atrevimento no que se refere a possíveis desorganizações do discurso administrativo e de uma resistência quanto à própria ideia de teorizar o corpo escolar de forma que ele se enquadre em um ou outro arcabouço epistemológico-científico. Tal perspectiva poético-discursiva quer, mais do que se afirmar enquanto ciência do corpo na Educação, empreender vias de deslocamento do corpo e da noção de corpo em sua relação com os arredores, com os outros, com o ambiente. Aí importam noções como trajeto, trilha, percurso, fronteira, limiar e limbo...

Compreender o corpo e seu espelhamento no discurso é olhar para sua materialidade por lentes que possam enxergá-lo integral e irrestritamente:

O chão transmuda-se: não é só chão, é matéria do traço de uma trilha/ narrativa, escritura de si. A narrativa é o traço da inscrição do corpo do sujeito no corpo da cidade, ressignificando-se na escrita de si. Corpo e espaço reescrevem o sujeito. (ORLANDI, 2014, p. 85).

Deslocamento dos sentidos, desorganização da ordem do espaço, resistência como premissa, passam a se estabelecer, assim, como marcas de um discurso 
que apresenta um sujeito assumidamente oscilante, à procura de conhecer-se $\mathrm{e}$, em percurso, à procura de quem o ouça e se interesse por suas demandas e urgências.

Nesse aspecto, este artigo considera o próprio ato pedagógico como um ato expressivo/enunciativo, que não pode ser abstraído da realidade, mas necessita assumir a relação entre corpo e presença como instância primordial de interação. Teatralidade e Performance apresentam-se, então, como dispositivos poético-discursivos capazes de repensar o conhecimento como um ato de criação estética, ou seja, nas relações entre sujeitos é que a construção do conhecimento encontra potencialidade de existência. É na experiência de estar com o outro, na ludicidade da troca humana e no partilhar de vivências que os atos performativos se estabelecem e se cruzam.

Le Breton (2009) propõe uma abordagem subjetiva quando fala na expressão das emoções e em percepções sensoriais, caso de estudos que se constituem por perspectivas performativas. Tal subjetividade tem ligação com a construção de significados por um viés relacional, pelo qual o argumento corpóreo se mostra mais potente do que investidas de ordem fisiológico-psicológica.

Ao se dedicar ao estudo de uma antropologia das emoções necessariamente confluente com uma antropologia do corpo, Le Breton (2009) se refere à emoção como um processo lúdico para a experimentação de paixões que se reinventam, se ressignificam e se expandem. Aí o papel da memória ganha destaque por permitir que um passado seja revivido no presente alargando a sensibilidade e a possibilidade de construção de sentidos para a experiência. É pela partilha, pelo encontro entre sujeitos, que a emoção corporificada pode nascer e ser comunicada (ou comungada) na vida cotidiana, na qual o campo do vivido ganha uma dimensão central, evidenciando a linguagem do corpo como principal agente de partilha da emotividade.

A emoção culturalmente compartilhada atravessa, desse modo, todo um aparato gestual inscrito no corpo. Considerando os gestos como figuras de ação que compilam a esfera simbólica cultural, Le Breton (2009) afirma que o sentido nunca pode ser dado e, sim, compreendido, especialmente no que tange à concepção de corpo enquanto conhecimento, como sentido prático da experiência de estar no mundo. Intimidade e subjetividade são, portanto, categorias fundamentais para pensar um sujeito corpóreo, ou, como defendemos neste ensaio, um sujeito que vive em um corpo teatralizado/performático. Mesmo que inserido em uma cultura, em uma organização social modeladora e definidora de certos conjuntos de práticas corporais violentas e repressoras (simbólicas ou não), seja o corpo teatralizado/performático capaz de aferir sentidos aos modos de experienciar a vida que impliquem menos precisão e mais polissemia, menos coerção e mais dialogia, menos ordem e mais caos... 
O estudo de Le Breton interessa a esta pesquisa por se configurar como um relevante arcabouço teórico para se pensar a formação de professores, a escola, a Educação e as relações entre estudantes e professores, ao trazer o enfoque para o universo lúdico, incluindo aí a linguagem e a emoção que transpassam os corpos dos sujeitos envolvidos nas práticas educacionais.

A análise dessas práticas só é possível, no entanto, pelo acontecimento de um corpo em presença. Um corpo que performa, que se autorrepresenta discursavemente. As relações entre Teatralidade, Performance e Educação são aqui, explicitadas, na forma de uma organização coerentemente posta, mas não finita. Ao mesmo tempo, este ensaio assume uma perspectiva que enfrenta essas relações e as destrincha, sem a menor intenção de esgotar sentidos ou se propor como qualquer tipo de resolução de problemas.

\section{Escrita teatralizada/performática}

Teatralidade e Performance se constituem como trilhas/narrativas que interessam ao campo da Educação, especialmente por se instaurarem como reescrita de si. Ambas se reconhecem enquanto tecnologia do corpo e concebem formas materiais de um mundo significante. É aqui que a noção de narrativa escrita se configura como processo de significação e tem um potencial de acessar "a maneira pela qual uma memória se diz em processos identitários, apoiados em modos de individuação do sujeito, afirmando/vinculando (seu "pertencimento") sua existência a espaços de interpretação determinados, consoantes a específicas práticas discursivas" (ORLANDI, 2014, p. 82).

Abre-se o espaço, então, neste trabalho, para se pensar o ato de narrar como processo, já desvinculado da relação com o gênero textual, como definido usualmente. Aqui é importante ressaltar que as narrativas escritas pelos diversos agentes da Educação precisam ser consideradas como dizeres teatralizados/ performáticos, extrapolando, também, a relação com um gênero específico. $\mathrm{O}$ ato de narrar é compreendido, neste viés, como possibilidade de inscrição dos corpos dos sujeitos em sua escrita e, consequentemente, da presentificação de suas histórias e trajetos nos textos que materializam.

Ao falarem de suas trajetórias, de suas experiências, os sujeitos também performam, também se utilizam de efeitos de Teatralidade por meio do desejo de dizer: dizer e $(\mathrm{m})$ Performance, que passeia entre diferentes dimensões e planos expressivos (verbais, visuais e/ou verbo-visuais). Tal acepção, ainda pouco explorada no campo da Educação, tem importantes contribuições no que 
se refere à interação entre corpo, escrita e sujeito, categorias fundamentais nas mais variadas esferas educativas de pesquisa (GONÇALVES, 2017).

Os tempos contemporâneos oferecem uma gama de narrativas vivenciais, em virtude da exposição mercadológica das memórias, biografias e autobiografias, testemunhos, posts sobre si, autorretratos (selfies), perfis em redes sociais, entrevistas, reality shows, blogs, vlogs, relatos de vida, relatos de pesquisa de imersão em primeira pessoa, narrações autorreferentes (ARFUCH, 2005, p. 51) e outros modelos que incluem o contar de si, com base em diferentes materialidades e planos expressivos.

Em “O que é um autor?", Foucault (2002) já falava de um sujeito da escrita em relação com o texto ou, mais especificamente, do modo como a escrita aponta para a figura do autor, esteja ela em uma posição exterior ou mesmo anterior ao próprio texto. De modo distinto, mas não discordante, Bakhtin concebe a figura do autor como aquele que cria, "mas vê sua criação apenas no objeto que ele enforma, isto é, vê dessa criação apenas o produto em formação e não o processo interno psicologicamente determinado" (BAKHTIN, 2003, p. 5).

Partindo da descentralização do sujeito autor, a pesquisa contemporânea pode se perguntar: quem é o autor na atualidade? Existe um status de autor a ser alcançado quando se escreve? Sujeito e autor resultam na forma de inscrição no texto que vai ao papel, à tela e a outros formatos de leitura? O que, do autor, é possível ver, ou, o que ele pretende revelar quando escreve e, na escrita, fala de si?

Klinger (2008), ao falar da relação do autor com o texto, defende, no campo da literatura, a noção de autoficção como um paradoxo entre um desejo de falar de si e o reconhecimento da impossibilidade de expressão da verdade na escrita sobre si. A autoficção, nesse aspecto, se relaciona com a Teatralidade e com a Performance, que, por sua vez, interessam-se pelos processos de desnaturalização do sujeito. O termo Performance, por exemplo, tem uma acepção, em inglês, ligada à atuação, desempenho, rendimento, mas aos poucos foi ganhando contornos mais específicos para o campo das artes e das ciências humanas, de modo que, a partir dos anos 1950, o termo tenha conseguido superar a dicotomia vida/arte. Do mesmo modo, a noção de Teatralidade supera, hoje, o campo do teatro, mesmo sem abrir mão de seu marco cultural e traduzindo-se como uma decorrência do contemplar que extrapola o campo artístico, podendo dispor de interessantes reflexões acerca do fenômeno teatral e suas reverberações em várias esferas de atividade humana.

Na defesa de Schechner (2006), ligada a qualquer atividade feita por um indivíduo ou grupo na presença de e para outro indivíduo ou grupo, a Performance é capaz de desvelar aspectos profundos e genuínos de uma cultura. Butler (2003), embora tenha se dedicado à aplicação da noção de Performance ao campo dos estudos de gênero (Gender Theory), apresenta relações com a 
artificialidade e com a encenação que contribuem, também, para a construção da perspectiva de autoficção, defendida por Klinger (2008). Ao apresentar o gênero como uma construção performática, ou seja, o performativo que sugere sempre o dramático, Butler (2003) argumenta que o gênero funciona como uma ficção regulatória que encarna uma performatividade, utilizando-se da repetição de normas e da dissimulação consciente e, ao mesmo tempo, ilusória.

Essa perspectiva interessa aos estudos da Teatralidade e da Performance por assumir a desconstrução do mito original, tomando o ato da Performance como cópia da cópia, sem espaços para um original instaurador, no qual funcionam e se mobilizam inúmeros efeitos de Teatralidade. A autoficção também não espera a existência de um sujeito modelo, prévio, como no caso da autobiografia, na qual o sujeito-autor pode copiar ou trair-se. Tanto para a Teatralidade e a Performance como para a autoficção literária o que importa é a construção simultânea (texto e vida) de uma personagem - o autor (KLINGER, 2008): é na relação entre escrita, Teatralidade e Performance, esta última como ato de inscrição do corpo em uma dada realidade/materialidade, na qual os sujeitos encontram um espaço para o dizer sobre si, que, aqui, nomeamos de escrita teatralizada/performática.

Para Lacan, o sujeito é aquilo que um significante representa para outro significante. Estruturado por representações, o sujeito é alguém que também representa. A partir do momento em que o homem põe tudo que o cerca em um palco de representação, ele também representa colocando-o a si mesmo em cena, em um ciclo perpétuo de reapresentação de si mesmo para o outro. Nesse ponto é possível pensar a narrativa em seu vínculo com as subjetividades e, por sua vez, a autoficção como uma Performance do autor, como um dizer sobre si por uma perspectiva dramática/teatral (KLINGER, 2008).

Embora a autofiç̧ão seja uma noção mais apropriada ao campo da literatura, ela é utilizada neste trabalho como forma de aproximação entre narrativa, Teatralidade e Performance, pensando os artifícios de escrita e até mesmo a identidade/alteridade do autor. As perguntas que se lançam nesse momento são: como olhar para as narrativas escritas no campo da pesquisa em Educação - escrita teatralizada/performática? O que fica dos sujeitos e de suas histórias quando estes se propõem a narrar fatos e fábulas sobre si em relação com os aspectos educacionais que cerceiam suas experiências de vida? Tentando respondê-las, seria prudente destacar que o próprio conceito de Performance deixaria entrever a teatralização da imagem do autor-sujeito. Quem é o sujeito escritor e quem é o sujeito-autor? Considerando a escrita como Performance em uma perspectiva de Teatralidade, essa é a pergunta que menos interessa responder, porque não se quer, nesse viés, um sujeito pleno, que pode ser refletido ou mascarado pelo texto que escreve. 
Nas palavras de Patrocínio (2016), o termo autoficção pode ser empregado para fazer referência a atos de evasão da intimidade, ou seja, a "extimidade" de quem escreve é performatizada/teatralizada na possibilidade de encontro com o outro e reconhecimento deste como agente fundamental da vida exposta valendo-se do desejo de expô-la. Ao se aproximar das narrativas escritas na perspectiva da autoficção, essa pesquisa abre espaço para que diferentes agentes da Educação performem/teatralizem também suas histórias e trajetórias relacionadas às vivências escolares de cada um:

É na reivindicação do outro que se fixa o gesto primeiro deste desejo de expor a intimidade. Não se trata de um exibicionismo, mas de uma formulação consciente do que será exposto a outrem, na qual se determina qual a identidade que será oferecida e esta é reconstruída pelo outro que a recebe e a desvela. (PATROCÍNIO, 2016, p. 1).

Embora os sujeitos colaboradores de uma pesquisa possam se propor a escrever/narrar com base em um material instrumentalizado, que pode, ousadamente, tentar criar escamas de neutralidade, eles performam/teatralizam ensaiam, organizam o pensamento, escolhem palavras, recortam perspectivas sobre como dizer o que querem. Aí o analista/pesquisador está sujeito ao visível e às invisibilidades do processo de análise, na tentativa de se debruçar sobre "instâncias de atuação do eu que se tencionam ou se reforçam, mas que, em todo caso, já não podem ser pensadas isoladamente” (KLINGER, 2008, p. 24).

Ao mobilizar as noções de Teatralidade e Performance na pesquisa em Educação, o autor precisa ser considerado como sujeito de uma atuação, representante de um papel na própria vida real, alguém que se expõe publicamente no ato da escrita, que corre riscos (e por isso joga entre o que pode/quer ou não dizer/revelar sobre si).

O mesmo acontece em outras formas de falar sobre si: entrevistas, crônicas, autorretratos, palestras... Formas que implicam um sujeito em Performance no devir, sob efeitos de Teatralidade, em seu contínuo processo de existência. No caso da narrativa compreendida, aqui, como escrita teatralizada/performática, o texto implica uma "dramatização de si que supõe, da mesma maneira que ocorre no palco teatral, um sujeito duplo, ao mesmo tempo real e fictício, pessoa (ator) e personagem" (KLINGER, 2008, p. 25). Tanto o sujeito narrador como o sujeito-autor se constituem e se constroem no percurso da escrita, em um emaranhado de letras e representações que desembocam em uma exposição de si mesmo, do sujeito enunciador e do espaço do qual enuncia. 
Tomando a autoficção como ponto de partida, a noção de escrita teatralizada/performática, apresentada neste artigo, tem a pretensão de quebrar o caráter naturalizado da autobiografia, a partir de uma forma discursiva que expõe o sujeito, questionando-o, ou seja, entendendo a subjetividade e a própria escrita como processos em construção.

A escrita teatralizada/performática se apresenta, então, como texto inacabado, improvisado, in process, como se o leitor pudesse assistir o processo de construção da narrativa. É aí que a escrita de si, nesta perspectiva, precisa ser lida pelas lentes da Teatralidade e da Performance, para além das qualidades estéticas ou linguísticas do texto. E este, por sua vez, encarado como lugar privilegiado de inscrição do sujeito e seu corpo no tempo e no espaço.

\section{Brevíssima conclusão}

Conclusão não é uma boa expressão para se despedir de um texto que transita entre a Teatralidade e a Performance na Educação por uma perspectiva discursiva. Tal como o corpo, inconcluso por natureza, a palavra, nunca finita, pula o ponto final e reconstrói seu sentido, deixando ecos e revozeamentos em um mundo de relações/encontros/atritos/embates/paixões.

Retomar as argumentações de Medviédev quanto à sua introdução crítica a uma poética sociológica e à proposição de uma ciência das ideologias, parece oportuno para este momento, já que no projeto discursivo de Bakhtin e o Círculo a centralidade da linguagem ultrapassa a análise de textos literários, invadindo e convidando outras áreas de estudo a beberem de suas contribuições:

Cada produto ideológico e todo seu "significado ideal" não estão na alma, nem no mundo exterior e nem no mundo isolado das ideias e dos sentidos puros, mas no material ideológico disponível e objetivo, na palavra, no som, no gesto, na combinação das massas, das linhas, das cores, dos corpos vivos, e assim por diante. Cada produto ideológico (ideologema) é parte da realidade social e material que circunda o homem, é um momento do horizonte ideológico materializado. Nãoimporta o que a palavra signifique, ela, antes de mais nada, está materialmente presente como palavra falada, escrita, impressa, sussurrada no ouvido, pensada no discurso interior, isto é, ela é sempre parte objetiva do meio social do homem. (MEDVIÉDEV, 2012, p. 50). 
Corpo e palavra são apresentados, nesse texto, não por uma ótica exclusiva, pelo contrário, há duas perspectivas de análise discursiva (Análise do Discurso de linha Francesa - AD e Análise Dialógica do Discurso - ADD) - correntes teóricas para as quais em nenhum momento se buscou intersecção - e dois dispositivos poético-discursivos (Teatralidade e Performance) sugeridos. Mais do que propor, o texto pretende se estabelecer como apoio teórico-prático àqueles pesquisadores que têm se dedicado a algum dos temas apontados e os objetos com os quais se encontram.

Pensar a pesquisa em Educação por alguma das perspectivas aqui desenvolvidas é assumir uma poética educacional sensível. Sensível, vale repetir, às demandas atuais por compreender os sujeitos da Educação, em um conjunto de diversidades e urgências que não pode, de maneira nenhuma, ser enquadrado em um quadro teórico-metodológico incapaz de suportar tais especificidades.

Corpo teatralizado/performático e escrita teatralizada/performática estão, destarte, atrelados não só à pesquisa em Educação, mas entre si, como campos interdependentes ávidos por binóculos e microscópios, por investigadores que se debrucem sobre a inegável presença de um sujeito (integral, único, irrepetível, singular, discursivo) cuja comunicação possa ser destrinchada/visitada/ frequentada pelas lentes da Teatralidade e da Performance.

\section{REFERÊNCIAS}

ARFUCH, L. El espacio biográfico. Buenos Aires: Fondo de Cultura Econômica, 2005. BAKHTIN, M. O autor e a personagem na atividade estética. In: BAKHTIN, M. Estética da Criação Verbal. Trad. Paulo Bezerra. 4. ed. São Paulo: Martins Fontes, 2003 [1920-1922].

BAKHTIN, M. Teoria do Romance I: A Estilística. Trad. Paulo Bezerra. São Paulo: Editora 34, 2015 [1934-36].

BUTLER, J. Problemas de gênero. Feminismo e subversão da identidade. Trad. Renato Aguiar. Rio de Janeiro: Civilização Brasileira, 2003.

CORNAGO, O. Atuar de verdade: a confissão como estratégia cênica. Urdimento, Florianópolis, v. 1, n. 13, p. 99-112, 2009. Disponível em: <http://digital.csic.es/bitstream/10261/24554/1/Urdimento_2009.pdf>. Acesso em: 12 out. 2017.

DIÉGUEZ, I. Um teatro sem teatro: a teatralidade como campo expandido. Revista Sala Preta, v. 14, p. 125-129, 2014. Disponível em: <https://www.revistas.usp.br/salapreta/ article/view/81758>. Acesso em: 28 set. 2017. 
DIÉGUEZ, I. Desmontagem Cênica. Rascunhos, Uberlândia, v. 1, n. 1, p. 5-12, 2014b. Disponível em: <http://www.seer.ufu.br/index.php/rascunhos/article/viewFile/27217/14875>. Acesso em: 30 set. 2017.

FERNANDES, S. Teatralidade e performatividade na cena contemporânea. Revista Repertório Teatro e Dança, v. 16, p. 11-23, 2011. Disponível em: <https://portalseer.ufba. br/index.php/revteatro/article/viewFile/5391/3860>. Acesso em: 30 set. 2017.

FLORENCE, J. Os efeitos de teatralidade. Trad. Silvia Balestreri. Revista Cena, Porto Alegre, n. 10, p. 1-18, 2011. Disponível em: <http://www.seer.ufrgs.br/index.php/cena/ article/view/25959/15362>. Acesso em: 20 set. 2017.

FOUCAULT, M. O que é um autor? Lisboa: Veja/Passagens, 2002 [1969].

HENRY, P. A Ferramenta Imperfeita. Campinas: Editora da Unicamp, 1992.

KLINGER, D. Escrita de si como performance. Revista Brasileira de Literatura Comparada. n. 12, 2008. Disponível em: <http://www.abralic.org.br/downloads/revistas/1415542249.pdf >. Acesso em: 10 set. 2017.

LE BRETON, D. As paixões ordinárias: antropologia das emoções. Petrópolis: Vozes, 2009.

LIGIÉRO, Z. Performance e Antropologia de Richard Schechner. Rio de Janeiro: Editora Mauad Ltda, 2012.

MEDVIÉDEV, P. N. O método formal nos estudos literários: introdução crítica a uma poética sociológica. Trad. Sheila Grillo e Ekaterina Vólkova Américo. São Paulo: Contexto, 2012. [1928].

MORSON, G. S. O cronotopo da humanicidade: Bakhtin e Dostoiévski. In: BEMONG, N. et al (Org.) Bakhtin e o Cronotopo: Reflexões, aplicações, perspectivas. Trad. Ozíris Borges Filho. São Paulo: Parábola Editorial, 2015.

GONÇALVES, J. C. Circo Negro: O Discurso Teatral em Perspectiva Dialógica. In: BRAIT, B.; SALVATERRA, A. (Org.). Dialogismo: Teoria e(m) Prática. São Paulo: Editora Terracota, 2014, v. 1, p. 267-279.

GONÇALVES, J. C. A Escola no Quintal da Cultura: teatralidades em perspectiva dialógica. Revista e-Curriculum, [S.1.], v. 15, n. 3, p. 594-614, set. 2017. ISSN 1809-3876. Disponível em: <http://dx.doi.org/10.23925/1809-3876.2017v15i3p594-614>. Acesso em: 4 out. 2017.

OLIVEIRA, O. B.; ALMEIDA, M. J. Considerações sobre a escrita e uma possibilidade para o ensino de Ciências. In: SCHMIDT. M. A.; GARCIA, T. M; HORN, G. Diálogos e Perspectivas de Investigação. Ijuí: Editora Unijuí, 2008.

ORLANDI, E. P. Parkour: corpo e espaço reescrevem o sujeito. Linguas e instrumentos linguísticos. n. 34. jul-dez, Campinas, 2014. 
PATROCÍNIO, P. A autoficção e as fronteiras entre o público e o privado. Revista Z Cultural, v. XI, n. 01, 2016. Disponível em: < http://revistazcultural.pacc.ufrj. $\mathrm{br} /$ ?ano $=42 \&$ edicao $=43>$. Acesso em: 30 set. 2017.

PEREIRA, M. de A. Performance e Educação: Relações, significados e contextos de investigação. Educação em Revista, Belo Horizonte, v. 28, n. 1, p. 289-312, 2012. Disponível em: <http://www.scielo.br/pdf/edur/v28n1/a13v28n1.pdf>. Acesso em: 8 set. 2017.

SAGASETA, J. Teorias de uma cena performática. In: CARREIRA, A; BAUMGÄRTEL, S. Nas fronteiras do representacional. Florianópolis: Letras Contemporâneas, 2014.

SCHECHNER, R. O que é performance? In: Performance studies: an introduction. 2nd. ed. New York \& London: Routledge, 2006. p. 28-51. Disponível em: $<$ http://www. performancesculturais.emac.ufg.br/up/378/o/O_QUE_EH_PERF_SCHECHNER.pdf $>$. Acesso em: 23 set. 2017.

Texto recebido em 29 de outubro de 2017. Texto aprovado em 31 de outubro de 2017. 
